\title{
Resistance of UV-perforated reduced graphene oxide on polystyrene surface
}

\author{
M.N. Nikolaeva ${ }^{1}$, A. N. Bugrov ${ }^{1,2}$, T. D. Anan'eva ${ }^{1}$, A. T. Dideikin ${ }^{3}$, M. K. Rabchinskii ${ }^{3}$, A. N. Ionov $^{3}$ \\ ${ }^{1}$ Institute of macromolecular compounds RAS, Bolshoy pr. 31, 199004 St. Petersburg, Russian Federation \\ ${ }^{2}$ Saint Petersburg Electrotechnical University "LETI", \\ ul. Professora Popova 5, 197376 St. Petersburg, Russian Federation \\ ${ }^{3}$ Ioffe Institute, Politekhnicheskaya ul. 26, 194021 St. Petersburg, Russian Federation \\ marianna_n@mail.ru, alexander.n.bugrov@gmail.com, anthracene@hq.macro.ru, \\ dideikin@mail.ioffe.ru, Rabchinskii@mail.ioffe.ru, ionov@tuch.ioffe.ru
}

PACS 36.20.-r; 68.65.Pq; 71.20.Rv; 72.80.Tm; 74.78.-w

DOI 10.17586/2220-8054-2018-9-6-793-797

\begin{abstract}
UV-perforated reduced graphene oxide flakes of large areas, some of them up to $500 \mu \mathrm{m}$ in diameter, have been produced on polystyrene surface. These flakes were formed during precipitation of UV-reduced graphene oxide composites based on polystyrene from benzene solutions by petroleum ether. Two composites based on polystyrene with molecular weights of 9,000 Da and 45,000 Da were synthesized to compare their conductive properties. Conditions of the formation of planar structures from UV-perforated reduced graphene oxide flakes were varied. So, resistances were compared for composites deposited from solutions with different concentrations and at different temperatures. Very low resistances for some flakes precipitated from $5 \mathrm{wt} . \%$ solution of composite of 9,000 Da molecular mass at the room temperature were obtained. The absolute values of measured resistances were found to be 1.5 orders of magnitude lower than resistance of copper. At the same time some, regions of graphene inclusions from $12 \mathrm{wt}$ \% solution of latter polystyrene composite demonstrated even lower resistance, almost 3 orders of magnitude lower than copper resistance. This result is explained by existence of superconducting component in the reduced graphene oxide inclusions. In the case of composites with graphene flakes produced from higher molecular weight polystyrene $(45,000 \mathrm{Da})$ resistance was high and varied from semiconducting values to non-conductive state.
\end{abstract}

Keywords: UV-perforated reduced graphene oxide, polystyrene, composite, resistance, superconductivity.

Received: 2 September 2018

\section{Introduction}

Graphene-like materials are very attractive for various brenches of practical use due to its unique electronic properties, including possible high-temperature superconductivity [1-7]. It was shown in [8] that some places of graphene oxide reduced at high temperature (RGO) [9] and obtained as planar structures on polystyrene surface have extremely low resistance. Absolute values of experimentally obtained resistance were 2 orders of magnitude lower than copper resistance. In this paper, we investigated the resistance of other graphene structures in the polystyrene composite, namely graphene oxide reduced by UV-perforation $\left(\mathrm{RGO}_{p}\right)$. Details of its producing can be found in $[10,11]$. The mechanism of the holes formation in the graphene oxide film is shown on Fig. 1.

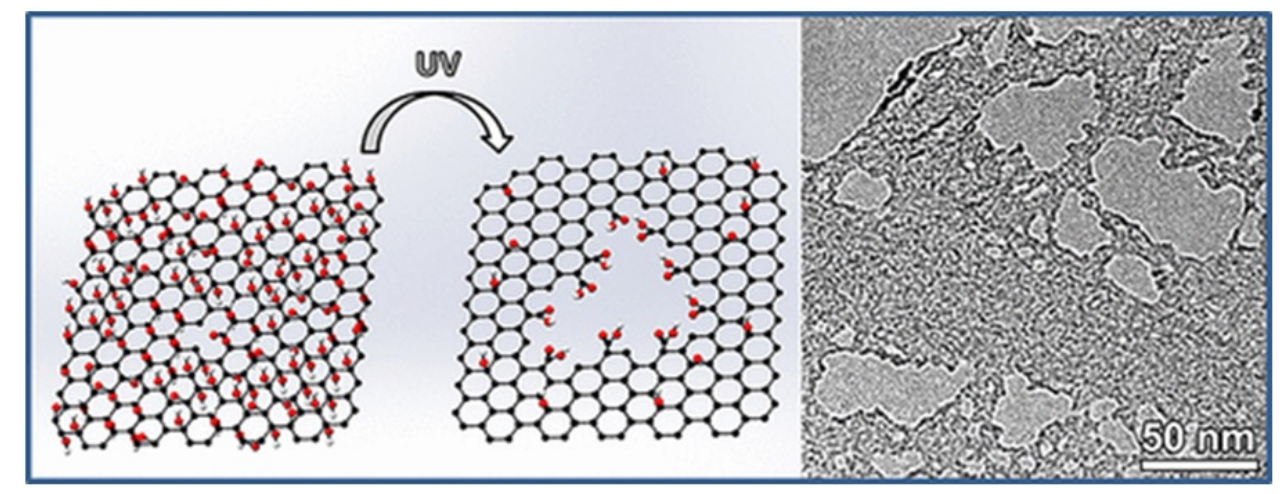

FIG. 1. Reduction scheme of thin graphene oxide (GO) films consisting of flakes with lateral size up to $100 \mu \mathrm{m}$ through soft ultraviolet irradiation under argon atmosphere [10] 
It was found in [10] that reduction leads to a significant decrease in the overall content of the basal-plane functional groups, namely, epoxides and hydroxyls, but with simultaneous increase in the total number of edgelocated carboxyl groups and formation of nanoscale holes.

Lateral sizes of individual $\mathrm{RGO}_{p}$ flakes were $10-100 \mu \mathrm{m}$ [10]. As it was previously, the maximum length of reduced graphene oxide flakes produced by heating at $800{ }^{\circ} \mathrm{C}$ (RGO) are only up to $8 \mu \mathrm{m}$ according to the SEM data [12]. Precipitation in [8] led to enlargement of RGO inclusion areas. So this chemical precipitation method of polystyrene composite from benzene can also be used for obtaining planar $\mathrm{RGO}_{p}$ flakes of sufficient size for electrical measurements.

It is important to note that RGO considered in $[8,12-15]$ was functionalized by 3 -(trimethoxysilyl)propyl methacrylate and can participate in radical polymerization with styrene [8], forming covalent bonds between RGO and polystyrene chains, similar to the work [16]. These features of RGO interaction with polystyrene can cause special mutual location of RGO flakes and its further self-organization under precipitation from solvents mixture leading to erasing of superconducting state as in [8]. The occurrence of holes in the RGO sheets after UV-irradiation can change location of (trimethoxysilyl)propyl methacrylate on their surface and affect the mutual self-organization the resulting $\mathrm{RGO}_{p}$ flakes. Thus, the aim of present study was to find out what conditions are needed to obtain the superconducting state for another form of reduced graphene oxide $-\mathrm{RGO}_{p}$.

\section{Experimental}

Surface modification technique of $\mathrm{RGO}_{p}$ and its further radical copolymerization with styrene as well as synthesis of RGO composite can be found in $[12,14]$. Only the content of the radical initiator, azobisisobutyronitrile (AIBN) was varied during the synthesis of composites in the reaction mixture, $1 \mathrm{wt.} \%$ and $0.2 \mathrm{wt.} \%$, correspondingly. Thus, the $\mathrm{RGO}_{p}$-polystyrene composites differed by molecular mass have been obtained. Molecular masses of composites were evaluated for additionally synthesized pure polystyrene. Polystyrene and composites based on it were synthesized by radical polymerization. The AIBN of $0.2 \mathrm{wt} . \%$ and $1 \mathrm{wt} . \%$ of the weight of the monomer were taken in the synthesis of pure polystyrene. The molecular weights of synthesized polystyrene using the above-mentioned amounts of initiator were evaluated using an Ubbelohde viscometer and were 9,000 Da and $45,000 \mathrm{Da}$, respectively. Since the amount of $\mathrm{RGO}_{p}$ introduced into the polystyrene is small and it acts along with styrene as a monomer due to surface modification by vinyl groups we assume that the molecular weights of the composites will be close to their values for unfilled polymer. The composite with molecular mass 9,000 Da further will be named Composite (1), with molecular mass 45,000 Da - Composite (2). The largest areas of graphene inclusions on the polystyrene surface were observed for the benzene/petroleum ether ratio of 1:1 [8]. In this regard, benzene/petroleum ether in ratio of 1:1 was used for $\mathrm{RGO}_{p}$ composite precipitation. This solvents ratio (1:1) was chosen also for production of sufficient $\mathrm{RGO}_{p}$ planar structures. Films of the polymer composite were deposited on glass substrate by casting through the dispenser. We proposed that the sizes of the $\mathrm{RGO}_{p}$ inclusions were dependent on kind of composite, concentration of solvent mixture, and deposition method on the glass substrate. Composite content in the solvents mixture was $5-12 \mathrm{wt} . \%$. Deposition was performed at room temperature and at the boiling point of benzene $\left(70^{\circ} \mathrm{C}\right)$.

Since areas of obtained $\mathrm{RGO}_{p}$ flakes were not too large to apply 4-probe method their resistance measurements were performed using 2-probe method. Steel needles with curvature radii of $15 \mu \mathrm{m}$ were used. Resistance values of $\mathrm{RGO}_{p}$ flakes were compared with ones corresponded to macroscopic copper substrate. Pressure on electrodes during measurements did not exceed $0.5 \mathrm{~g} / \mu \mathrm{m}^{2}$ as in [8].

\section{Results and discussion}

The $\mathrm{RGO}_{p}$ flake distribution for both composites after deposition was irregular on the polystyrene surface, and their sizes were many fold different from each other in the same way as in [8]. However, special differences in shape and size were observed for the synthesized $\mathrm{RGO}_{p}$ composites. Particularly, for the Composite (1) maximal observed diameters of $\mathrm{RGO}_{p}$ flakes in planar dimensions deposited from $5 \mathrm{wt} . \%$ solution were approximately $150 \mu \mathrm{m}$ without heating and $300 \mu \mathrm{m}$ when glass substrate was heated up to $70^{\circ} \mathrm{C}$. Maximal diameters of $\mathrm{RGO}_{p}$ inclusions in the Composite (2) deposited from $5 \mathrm{wt} . \%$ solution reached $300 \mu \mathrm{m}$ without heating and were up to $500 \mu \mathrm{m}$ in the opposite case. When concentrated solutions were used, maximal diameters of $\mathrm{RGO}_{p}$ inclusions for both considered composites were even larger. There was one more difference between these two composites: for the Composite (2) $\mathrm{RGO}_{p}$ shapes were close to spherical, for the Composite (1) $\mathrm{RGO}_{p}$ shapes were practically planar, rising above the surface of polystyrene not higher than $100 \mathrm{~nm}$. So, the objects of our investigation had turned out to be the multilayered $\mathrm{RGO}_{p}$ flakes obtained as a result of self-organization during precipitation process. 
Since during the precipitation process the polymer coils were tightened, some tensions between the filler and polystyrene led to the release of the $\mathrm{RGO}_{p}$ of each coil from the polymer matrix. In this manner, separate $\mathrm{RGO}_{p}$ particles coalesced into large flakes. Due to the holes in the $\mathrm{RGO}_{p}$ sheets attaching of the 3-(trimethoxysilyl)propyl methacrylate to them will largely depend on the edge groups around cavities. Thus, the molecules of the organosilicon modifier, which are very close to each other at the edges of the hole, can interact between themselves. This process may cause additional tensions between releasing $\mathrm{RGO}_{p}$ sheets and change way of their further selforganization. As a result, new types of $\mathrm{RGO}_{p}$ flakes on the polystyrene surface were formed. So, these $\mathrm{RGO}_{p}$ flakes of different sizes and shapes being deposited from the composites' solutions on glass substrate demonstrated special current-voltage characteristics.

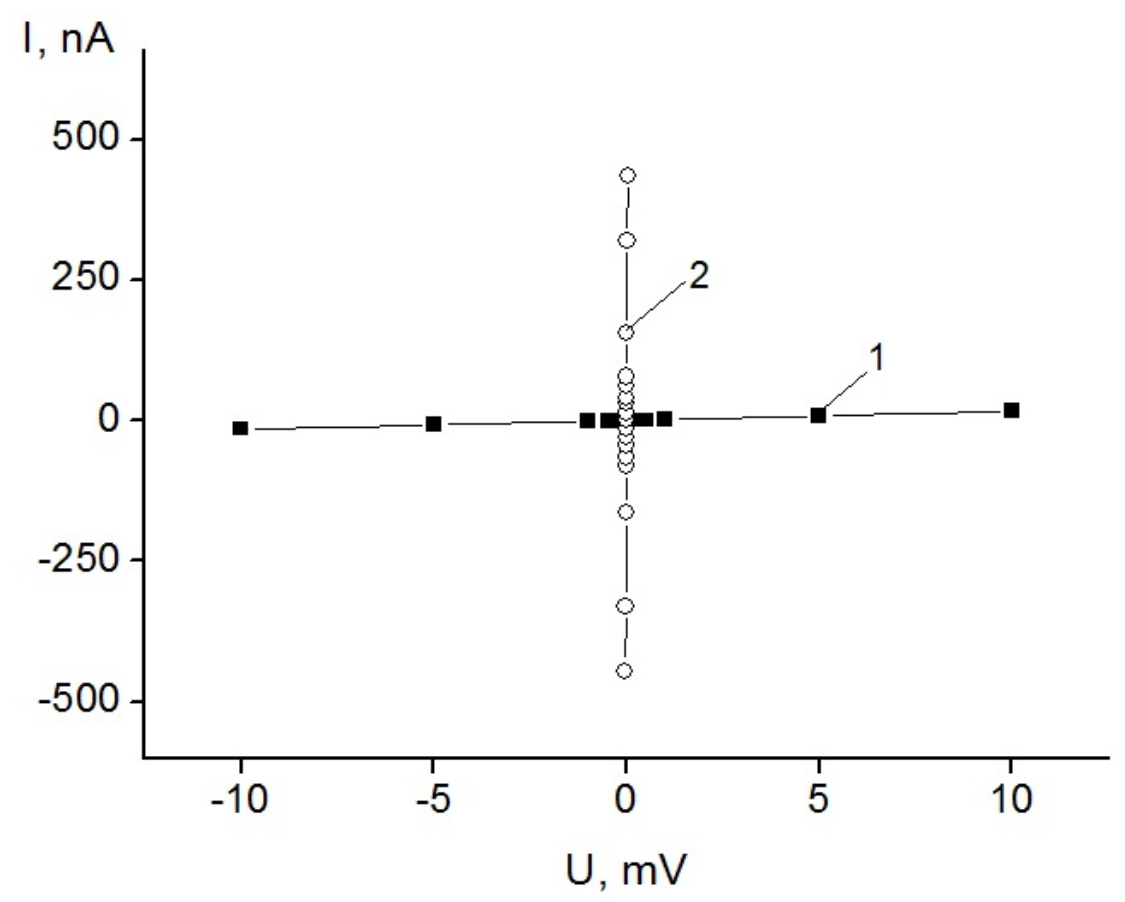

FIG. 2. Current-voltage characteristic of $1-\mathrm{RGO}_{p}$ flakes deposited from polystyrene composite of 45,000 Da, distance between electrodes $10 \mu \mathrm{m}$, concentration of solution 5 wt. $\%$; 2 - currentvoltage characteristic of copper

To measure the resistance, sufficiently large flakes of $\mathrm{RGO}_{p}$ with a diameter of $150 \mu \mathrm{m}$ or more were used. Resistance was evaluated from current-voltage characteristics (Fig. 2,3). In general, the resistance of $\mathrm{RGO}_{p}$ flakes of Composite (1) obtained without heating lied in the range of $0.6-7 \Omega$ for $12 \mathrm{wt} . \%$ composite and in interval of $20-40 \Omega$ for 5 wt.\% composite. Resistance of some $\mathrm{RGO}_{p}$ flakes approached $0.13 \Omega$ for 12 wt.\% and $15 \Omega$ for 5 wt.\% composites without heating during deposition (Fig. 3, curves 1 and 2). The common resistances for $\mathrm{RGO}_{p}$ flakes of this composite when $\mathrm{RGO}_{p}$ flakes were formed practically immediately being deposited from precipitated composite solution on heated glass substrate were up to 1 order of magnitude lower than copper resistance and were about $5-12 \Omega$. The resistance of copper substrate was approximately $67 \Omega$ (Fig. 2, curve 2; Fig. 3, curve 3 ). As one can readily see, a temperature increase in the case of low-molecular weight Composite (1) did not significantly affect resistances of deposited $\mathrm{RGO}_{p}$ flakes. Since relatively small polymer coils are divided by the solvent this result would be explained that sufficiently long distances are needed to overcome by separate $\mathrm{RGO}_{p}$ sheets of every polymer molecule for self-organization into larger structures.

The $\mathrm{RGO}_{p}$ flakes in the case of the Composite (2) exhibited both a non-conducting state and a low conducting state in the range of hundreds of $\mathrm{k} \Omega$ and $\mathrm{M} \Omega$. One of the lowest values of resistance obtained for this composite was $670 \mathrm{k} \Omega$ (Fig. 2, curve 1). We suppose that fast self-organization of $\mathrm{RGO}_{p}$ inclusions due to the heating in the process of deposition on glass substrate can cause irregular and chaotic interaction of relatively close located $\mathrm{RGO}_{p}$ sheets. In this case, many defects in $\mathrm{RGO}_{p}$ flakes prevent high conductivity.

The resistance of $\mathrm{RGO}_{p}$ flakes was dependent on distance between measuring electrodes. The distance increase in the case of the Composite (1) caused sharp resistance amplification, as was seen in [8]. At the same time, for Composite (2), the distance between measuring electrodes very slightly influenced resistance values. Moreover, 


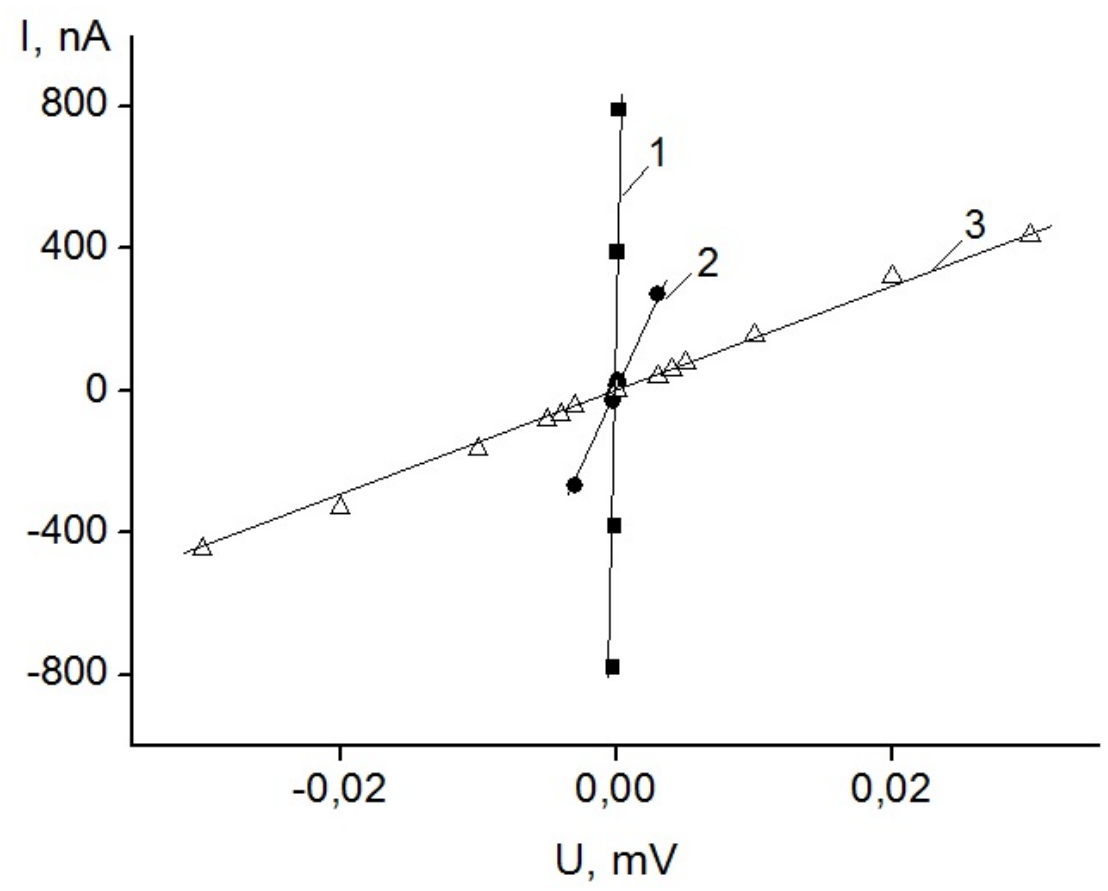

FIG. 3. Current-voltage characteristics of $\mathrm{RGO}_{p}$ flakes deposited from polystyrene composite of 9,000 Da, distance between electrodes $10 \mu \mathrm{m}$ : 1 - concentration of solution 12 wt.\%, $2-$ concentration of solution 5 wt. $\% ; 3$ - current-voltage characteristic of copper

the distance between the measuring electrodes for Composite (2) had a very weak effect on the resistance values. These values were almost equal even when the distance between electrodes reached 200-300 $\mu \mathrm{m}$.

The obtained results of very low resistances for $\mathrm{RGO}_{p}$ flakes from the Composite (1) can be explained by the existence of superconducting phase in the $\mathrm{RGO}_{p}$ flakes at the room temperature. We suppose since there are theoretical papers predicting possibility of superconducting state for graphene at room temperature under special conditions $[6,17-19]$ the self-organization of separate $\mathrm{RGO}_{p}$ sheets during precipitation and further deposition on the glass substrate possibly can satisfy these conditions. The electric properties of these multilayered $\mathrm{RGO}_{p}$ flakes obtained as a result of self-organization during precipitation process of Composite (1) can be similar to finely dispersed pyrolytic graphite having superconducting inclusions [20]. Obtained resistance values are in consent with our previous work [8] as also with [21] where it was shown for RGO/polysterene composite that Josephson oscillations and Shapiro steps exist at room temperature.

\section{Conclusions}

Large planar $\mathrm{RGO}_{p}$ structures (hundreds of micrometers in diameter) from two $\mathrm{RGO}_{p}$ /polystyrene composites differing by molecular masses were obtained on polystyrene surface. For this purpose, precipitation of composites with perforated reduced graphene oxide based on the polystyrene from benzene was used. Precipitation of both composites was performed by petroleum ether in ratio $1: 1$ to benzene. The temperature of further $\mathrm{RGO}_{p}$ deposition on glass substrate strongly influenced on the sizes and resistances of obtained $\mathrm{RGO}_{p}$ flakes. Thus, heating to $70{ }^{\circ} \mathrm{C}$ allowed deposit larger, up to $500 \mu \mathrm{m}$, structures. At the same time, such enlargement caused decrease of conductivity to non-conductive state. Sizes of $\mathrm{RGO}_{p}$ structures can be enlarged by increasing of composites concentration at the room temperature as well. In this case, the $\mathrm{RGO}_{p}$ flakes' enlargement, otherwise, causes a significant decrease of resistance. The resistance of some rare planar inclusions measured by steel needles was found to be up to 3 orders of magnitude lower than the resistance measured for the copper substrate.

\section{References}

[1] Novoselov K.S., Fal'ko V.I., Colombo L., Gellert P.R., Schwab M.G., Kim K.A. Roadmap for Graphene Nature. Nature, 2012, 490, P. $192-200$.

[2] Huang X., Yin Z., et al. Graphene-based materials: Synthesis, Characterizations, Properties, and Applications. Small, 2011, 7(14), P. $1876-1902$

[3] Potts J.R., Dreyer D.R., Bielawski C.W., Ruoff R.S. Graphene-Based Polymer Nanocomposites. Polymer, 2011, 52, P. 5-25. 
[4] Kostromin S., Saprykina N., Vlasova E. et al. Nanocomposite polyazomethine/reduced graphene oxide with enhanced conductivity. Journal of Polymer Research, 2017, 24(12), P. 211.

[5] Uchoa B., Castro Neto A.H. Superconducting states of pure and doped graphene. Phys Rev Letters, 2007, 98 P. 146801-1-146801-4.

[6] Chapman J., Su Y., Howard C.A., et al. Superconductivity in Ca-doped graphene laminates. Sci. Rep., 2016 , 6, P. 23254.

[7] Tonnoir C., Kimouche A., Coraux J., et al. Induced superconductivity in graphene grown on Rhenium. Phys. Rev. Lett., 2013, 111(24), P. 246805.

[8] Nikolaeva M.N., Bugrov A.N., Anan'eva T.D., et. al. Resistance of reduced graphene oxide on polystyrene surface. Nanosystems: physics, chemistry, mathematics, 2018, 9(4), P. 496-499.

[9] Dideykin A., Aleksenskiy A.E., Kirilenko D., et. al. Monolayer graphene from graphite oxide. Diam. Relat. Mat., 2011, 20(2), P. 105-108.

[10] Rabchinskii M.K., Shnitov V.V., Dideikin A.T., et.al. Nanoscale Perforation of Graphene Oxide during Photoreduction Process in the Argon Atmosphere. J. Phys. Chem. C, 2016, 120(49), P. 28261-28269.

[11] Aleksenskii A.E., Vul' S.P., Dideikin A.T., et.al. Etching of wrinkled graphene oxide films in noble gas atmosphere under UV irradiation. Nanosystems: physics, chemistry, mathematics, 2016, 8(1), P. 81-86.

[12] Nikolaeva M.N., Bugrov A.N., Anan'eva T.D., et al. Conductive properties of the composite films of graphene oxide based on polystyrene in a metal-polymer-metal structure. Russ. J. Appl. Chem., 2014, 87(8), P. 1151-1155.

[13] Nikolaeva M.N., Gushchina E.V., Dunaevskii M.S., et al. The influence of substrate material on the resistance of composite films based on reduced graphene oxide and polystyrene. Nanosystems: physics, chemistry, mathematics, 2017, 8(5), P. 665-669.

[14] Khairullin A.R., Nikolaeva M.N., Bugrov A.N. Resistance of the composite films based on polystyrene and graphene oxide. Nanosystems: physics, chemistry, mathematics, 2016, 7(6), P. 1055-1058.

[15] Nikolaeva M.N., Anan'eva T.D., Bugrov A.N., et.al. Correlation between structure and resistance of composites based on polystyrene and multilayered graphene oxide. Nanosystems: physics, chemistry, mathematics, 2017, 8(2), P. 266-271.

[16] Yevlampieva N., Bugrov A., Anan'eva T., et al. Soluble poly (methyl methacrylate) composites containing covalently associated zirconium dioxide nanocrystals. Am. J. Nano Res. and Appl., 2014, 2(2), P. 1-8.

[17] Esquinazi P., Heikkilä T.T., Lysogorskiy Y.V., et.al. On the superconductivity of graphite interfaces. JETP Letters, 2014, 100(5), P. 336-339.

[18] Scheike T., Bhlmann W., Esquinazi P., et. al. Can doping graphite trigger room temperature superconductivity? Evidence for granular high-temperature superconductivity in water-treated graphite powder. Advanced Materials, 2012, 24(43), P. 5826-5831.

[19] Volovik G.E., Pudalov V.M. Graphite on graphite. JETP Letters, 2016, 104(12), P. 880-882.

[20] Saad M., Gilmutdinov I.F., Kiiamov A.G., et al. Observation of Persistent Currents in Finely Dispersed Pyrolytic Graphite. JETP Letters, 2018, 107(1), P. 37-41.

[21] Ionov A.N. Josephson-Like Behaviour of the Current-Voltage Characteristics of Multi-graphene Flakes Embedded in Polystyrene. J. Low Temp. Phys., 2016, 185(5-6), P. 515-521. 